RIMS Analysis of lon Induced

Fragmentation of Molecules Sputtered from an Enriched U308 Matrix

D. Willingham, M. R. Savina, K. B. Knight, M. J. Pellin, I. D. Hutcheon

April 23, 2012

Journal of Radioanalytical and Nuclear Chemistry 
This document was prepared as an account of work sponsored by an agency of the United States government. Neither the United States government nor Lawrence Livermore National Security, LLC, nor any of their employees makes any warranty, expressed or implied, or assumes any legal liability or responsibility for the accuracy, completeness, or usefulness of any information, apparatus, product, or process disclosed, or represents that its use would not infringe privately owned rights. Reference herein to any specific commercial product, process, or service by trade name, trademark, manufacturer, or otherwise does not necessarily constitute or imply its endorsement, recommendation, or favoring by the United States government or Lawrence Livermore National Security, LLC. The views and opinions of authors expressed herein do not necessarily state or reflect those of the United States government or Lawrence Livermore National Security, LLC, and shall not be used for advertising or product endorsement purposes. 


\title{
RIMS Analysis of Ion Induced Fragmentation of Molecules Sputtered from an Enriched $\mathrm{U}_{3} \mathrm{O}_{8}$ Matrix
}

\author{
D. Willingham ${ }^{1}$, M.R. Savina ${ }^{1}$, K.B. Knight ${ }^{2}$, M.J. Pellin ${ }^{1}$, I.D. Hutcheon ${ }^{2}$ \\ ${ }^{1}$ Argonne National Laboratory, Argonne, IL \\ ${ }^{2}$ Lawrence Livermore National Laboratory, Livermore, CA
}

\begin{abstract}
RIMS was used to measure the composition of the sputtered flux from $15 \mathrm{keV} \mathrm{Ga}^{+}, \mathrm{Au}^{+}, \mathrm{Au}_{2}{ }^{+}$and $\mathrm{Au}_{3}{ }^{+}$ primary ions impacting a ${ }^{235} \mathrm{U}$ enriched $\mathrm{U}_{3} \mathrm{O}_{8}$ standard. We demonstrate that molecular fragmentation decreases as the primary ion mass and nuclearity increases. SRIM calculations show that cluster ions $\left(\mathrm{Au}_{2}{ }^{+}\right.$and $\left.\mathrm{Au}_{3}{ }^{+}\right)$deposit more of their energy via direct knock-ons with near-surface target atoms, whereas monatomic ions $\left(\mathrm{Ga}^{+} \mathrm{and}^{\mathrm{Au}}{ }^{+}\right)$ penetrate much deeper into the target sub-surface region. We correlate these results to the experimental observations by showing that increased cluster ion sputter yields partition the projectile energy over a larger number of sputtered molecules. Therefore, while cluster ions deposit more total energy into the near surface region of the target compared to monatomic ions, the energy per molecule decreases with projectile mass and nuclearity. Less energy per molecule decreases the number of U-O bond breaks and, consequently, leads to a decrease in molecular fragmentation. Additionally, the extent of molecular fragmentation as a function of ion dose was evaluated. We show that molecular fragmentation increases with increased ion dose; primarily as a result of sub-surface chemical damage accumulation. The relative intensity of this effect appears to be projectile independent.
\end{abstract}

Keywords $\quad$ RIMS, Enriched uranium, Cluster ions, Useful yield, SRIM

\section{Introduction}

The increasing threat of nuclear weapons development has prompted the use of a number of mass spectrometry techniques charged with the task of determining the isotopic composition of trace amounts of radionuclides from a diverse set of materials [1-7]. A major focus for these types of measurements is on improving 
the sensitivity for the detection of uranium and transuranic isotopes in the presence of isobaric interferences without the need for complex and time-consuming sample preparation methods. Recently, secondary ion mass spectrometry (SIMS) has shown promise as an effective tool for the analysis of nuclear materials with high sensitivity and minimal sample preparation [8-11]. The sensitivity of SIMS is often defined by useful yield: the number of ions detected over the number of atoms removed during the analysis. SIMS analysis of $\mathrm{U}_{3} \mathrm{O}_{8}$ standards has achieved useful yields of 1-2\% using high mass resolution, multi-collector instruments [9].

Analytical resonance ion mass spectrometry (RIMS) uses wavelength tunable lasers to selectively ionize atoms desorbed from solid surfaces either by ion sputtering or laser heating. The resulting sputtered flux is composed of secondary ions and neutrals characteristic of the sample surface chemistry. In our RIMS instruments, the ion component of the sputtered flux is suppressed electrostatically prior to photoionization of the sputtered neutrals. The neutral atoms of interest are then selectively ionized using one or two lasers with wavelengths chosen to match specific atomic resonance transitions. These electronically excited atoms are ionized using an additional laser with a wavelength corresponding to an autoionizing resonance of the element of interest. Photoions are extracted into a time-of-flight mass spectrometer (TOF-MS) and detected using a multi-channel plate (MCP) ion detector.

Transitioning from standard samples to more complex materials can become increasingly more complicated due to the presence of isobaric interferences. While large geometry SIMS instruments have been used to analyze uranium oxide reference materials with high precision, SIMS can be hindered by mass coincidences from same-mass isotopes, hydrides and other molecular compounds [9]. RIMS achieves its selectivity spectroscopically and, therefore, is capable of overcoming these isobaric limitations. Unfortunately, it is this very selectivity that often limits the useful yield of RIMS measurements. The useful yield of RIMS experiments depends heavily on the sample being analyzed; i.e. the useful yield for uranium atoms from reduced uranium metal is significantly larger than from $\mathrm{U}_{3} \mathrm{O}_{8}$. This is primarily a result of variations in the composition of the sputtered flux. Previous work [unpublished] has shown that ion sputtering of $\mathrm{U}_{3} \mathrm{O}_{8}$ produces mainly uranium oxide $\left(\mathrm{UO}_{\mathrm{x}}\right)$ molecules rather than uranium atoms. Since RIMS is only sensitive to the specific element of interest, the useful yield for uranium atoms from these materials is significantly reduced. We investigate several ion sputtering regimes to better understand the mechanisms that lead to projectile dependent molecular fragmentation. 


\section{Experimental}

A CRM U500 standard material was used for all analysis reported herein. The CRM U500 was composed of sintered aggregates of micrometer sized $\mathrm{U}_{3} \mathrm{O}_{8}$ grains pressed into indium foil. Additionally, the CRM U500 was isotopically enriched in ${ }^{235} \mathrm{U}$ to a $1: 1$ ratio with ${ }^{238} \mathrm{U}$. The CRM U500 standard material was mounted to a sample holder and entered into the vacuum chamber without any further sample preparation.

RIMS analyses were performed on the CHARISMA instrument at Argonne National Laboratory; described in detail elsewhere [12]. Briefly, a solid target is sputtered using a $15 \mathrm{keV}$ ion beam $\left(\mathrm{Ga}^{+}, \mathrm{Au}^{+}, \mathrm{Au}_{2}^{+}\right.$or $\left.\mathrm{Au}_{3}^{+}\right)$from a liquid metal ion source (IOG 25 , Ionoptika Ltd.) and focused to a spot size of $\sim 10 \mu \mathrm{m}$. Secondary ions generated from the ion bombardment are ejected using a $+4 \mathrm{kV}$ bias voltage. After a short, field-free duration, the secondary neutrals are intersected with three, pulsed laser beams at $\sim 1 \mathrm{~mm}$ from the sample surface. The lasers are wavelength tunable Ti:sapphire systems that have been described in detail elsewhere $[12,13]$. The laser wavelengths are tuned to excite two resonance transitions and an autoionizing state to selectively ionize neutral uranium atoms within the sputtered flux. The 3-color, 3-photon RIMS scheme for uranium atoms used herein was adapted from work by Schumann et al. [14] and is described in detail by Isselhardt and co-workers [15]. The resonantly ionized uranium atoms are then extracted into a reflectron-type TOF-MS at $+2 \mathrm{kV}$ and focused onto a MCP ion detector. Single ion event signals from the ion detector were digitized by a time-to-digital board (P7889, FAST ComTec GmbH.). The resulting mass spectra are typically a summation of 10,000 individual analysis cycles acquired at a repetition rate of $1 \mathrm{kHz}$. For experiments performed at increased primary ion duty cycle, a second primary ion pulse was added to each analysis cycle ranging from 5 to $400 \mu \mathrm{s}$; permitting duty cycles as large as $40 \%$.

Although specifically targeted at neutral uranium atoms, the RIMS scheme used herein also inadvertently ionizes $\mathrm{UO}_{\mathrm{x}}$ molecules. The photoionization of $\mathrm{UO}_{\mathrm{x}}$ molecules originates from a $1+1$ resonance enhance multiphoton ionization (REMPI) process involving the $1^{\text {st }}$ resonance laser $(415.511 \mathrm{~nm})$ from the RIMS scheme. Despite the small photoionization cross-section for this process compared to uranium atoms, the laser power (150 - $500 \mathrm{~mW})$ used in these experiments is high enough to ionize both $\mathrm{UO}$ and $\mathrm{UO}_{2}$ species.

\section{Results and discussion}

The nature of ion-solid interactions is primarily governed by the efficiency of energy transfer from the primary ion to the surface and sub-surface atoms. Ion sputtering can be described by a sequence of elastic collisions 
between point particles [16]. In this process, the bombarding ion transfers its energy to the target atoms, thereby initiating a series of collision cascades within the near-surface region; although much of the energy of the projectile is deposited much deeper within the bulk. Collisions that recoil back through the sample surface result in sputtered material; whereas, collisions occurring at greater penetration depths lead to sub-surface chemical damage. Until recently, ion beam analysis of surfaces used only monatomic ions such as $\mathrm{Ar}^{+}, \mathrm{Ga}^{+}$and $\mathrm{In}^{+}$; however, the advent of cluster ions sources has led to a paradigm shift in the way we think about ion-solid interactions. Cluster ion beams such as $\mathrm{Au}_{3}{ }^{+}, \mathrm{Bi}_{3}{ }^{+}$and $\mathrm{C}_{60}{ }^{+}$provide $\sim 3$ orders of magnitude increase in ion yield as compared to monatomic ion sources $[17,18]$. This is because, unlike the collision cascade generate by monatomic ions, cluster ions deposit a majority of their energy within the first few nanometers of the surface, resulting in significant increases in sputter yield [19]. The observed cluster ion sputter yields increase non-linearly with cluster nuclearity; indicating a significant deviation from the collision cascade model.

In addition to primary ion dependent variations in sputter yield, it is possible to measure the kinetic energy distribution of sputtered material using sophisticated photoionization techniques [20-23]. These methods can provide insight into the mechanism of energy transfer from the primary ion to the surface and sub-surface atoms. The analysis of molecular solids, however, is significantly more complicated due to the partitioning of energy imparted to the sputtered molecules into various fragmentation pathways. This makes it increasingly difficult to infer specific details about the internal energy distribution of the sputtered molecules from the kinetic energy distribution. The complexity of the mass spectra obtained from molecular solids, however, can be used to our advantage in this situation. The mass spectra of molecular species often contain parent mass peaks and fragment mass peaks. The extent of fragmentation can be determined simply by taking the ratio of ion counts in the parent mass over the ion counts in the fragment masses $(M / F)$. Previous work has indicated that the M/F of poly-aromatic hydrocarbons (PAHs) as well as the specific fragmentation pathway - carbon loss compared to hydrogen loss - can be correlated to the average internal energy of the sputtered flux [24, 25].

Variations in the extent of fragmentation of sputtered molecules are known to be projectile dependent. Cluster ion sputtering of polymers has been shown to increase the probability of direct impacts (or knock-ons) with target atoms compared to monatomic ions resulting in ejection of predominantly molecular fragments [26, 27]. In contrast, previous work comparing the sputtering of PAHs with $\mathrm{Au}^{+}$and $\mathrm{C}_{60}{ }^{+}$showed that molecular fragmentation was reduced with cluster ion sputtering [25]. It is clear that the extent of molecular fragmentation in any system is 
heavily dependent of the material being analyzed as well as the nuclearity and mass of the primary ion probe. The efforts described herein focus on ion sputtering of a uranium oxide with a number of different primary ions $\left(\mathrm{Ga}^{+}\right.$, $\left.\mathrm{Au}^{+}, \mathrm{Au}_{2}^{+}, \mathrm{Au}_{3}^{+}\right)$. By comparing the ratio of the parent mass to the fragment mass ions as a function of primary ion mass and nuclearity, we aim to determine the effects of cluster ion sputtering on the useful yield of uranium atoms from $\mathrm{U}_{3} \mathrm{O}_{8}$.

Mass spectra are shown in Figure 1. Peaks correspond to resonantly ionized uranium atoms and $\mathrm{UO}_{\mathrm{x}}$ molecules ionized via a 1+1 REMPI process. Photoionization cross sections for each of these species have been calculated previously [unpublished] using the saturation ionization technique [28]. This technique allows for direct conversion of the observed ion signals into the composition of the sputtered flux. The data in Table 1 illustrates the need to adjust each ion signal according its cross-section in order to obtain the correct $\mathrm{M} / \mathrm{F}$ ratios and percent compositions of uranium atoms in the sputter flux. The $\mathrm{M} / \mathrm{F}$ ratios in each case consider the $\mathrm{UO}_{2}$ and $\mathrm{UO}$ as two separate parent masses with $U$ as the fragment mass in each case. This treatment of the data is used for simplicity and does not include the full complement of known fragmentation pathways for gas phase $\mathrm{UO}_{\mathrm{x}}$ molecules [29].

The $\mathrm{M} / \mathrm{F}$ ratios $\left(\mathrm{UO}_{2} / \mathrm{U}\right.$ and $\left.\mathrm{UO} / \mathrm{U}\right)$ for each primary ion as a function of its mass are shown in Figure 2. Clearly, the $\mathrm{M} / \mathrm{F}$ increases and, therefore, the extent of fragmentation of $\mathrm{UO}_{\mathrm{x}}$ molecules to uranium atoms decreases with increased mass of the primary ion. In addition this decreased fragmentation is enhanced non-linearly as a function of primary ion nuclearity; i.e. the $\mathrm{M} / \mathrm{F}$ ratio $\left(\mathrm{UO}_{2} / \mathrm{U}\right)$ from $\mathrm{Au}_{3}{ }^{+}$bombardment is $8.5 \mathrm{x}$ larger than that of $\mathrm{Au}^{+}$, which has $1 / 3$ the mass. These results can be investigated further using Monte-Carlo computational modeling methods [30]. The stopping and range of ions in matter (SRIM) 2011 software was used to model the ion-atom collisions of $\mathrm{U}_{3} \mathrm{O}_{8}$ with $\mathrm{Ga}^{+}, \mathrm{Au}^{+}, \mathrm{Au}_{2}{ }^{+}$and $\mathrm{Au}_{3}{ }^{+}$. This computational approach deviates from our experimental setup in two significant aspects. First, the model contains a stoichiometric arrangement of $U$ and $\mathrm{O}$ atoms with the density and surface binding energy of $\mathrm{U}_{3} \mathrm{O}_{8}$, but without treatment of chemical bonding configurations. Secondly, SRIM only models monatomic primary ions; therefore, the cluster ions were approximated by running the

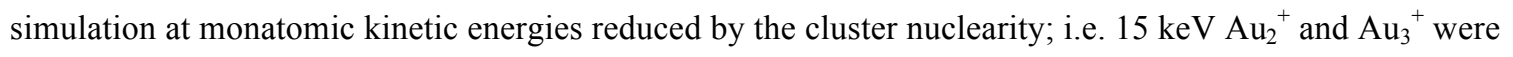
approximated by $\mathrm{Au}^{+}$at 7.5 and $5 \mathrm{keV}$ respectively. This method for approximating cluster ion sputtering has been shown to be valid for materials with large sublimation energies where the nonlinear sputter yield enhancements are small [31]. Although it is not possible to make a direct comparison to the experimental results, the data provided by 
the SRIM calculation provides valuable insight into the mechanism of energy transfer between the primary ion and the target atoms.

The data in Figure 3 from the SRIM simulations show the number of direct knock-ons of the primary ion with target atoms as a function of depth from the surface. Here we can see that the total number of knock-ons increases as a function of primary ion mass and nuclearity allowing for more direct transfer of energy from the primary ion to the target atoms. Additionally, the sampling depth of these knock-ons becomes shallower with increasing primary ion mass and nuclearity, indicating that cluster ions deposit energy much closer to the sample surface than monatomic ions.

Figure 4 shows that although the total energy imparted to the sputtered flux increases, the energy per secondary species decreases with increasing primary ion mass and nuclearity. This observation provides a direct correlation between the experimental measurements and the computational model. As the primary ion mass and nuclearity increases, the probability of direct knock-ons with the target atoms increase and more energy is imparted from the primary ion to the target atoms. However, because the sputter yield increases as well, the total energy imparted from the primary ion is partitioned over a much larger sputtered flux causing the energy per secondary species to decrease. Less energy per secondary species means less energy available to break U-O bonds and, therefore, less fragmentation of $\mathrm{UO}_{\mathrm{x}}$ molecules. This computational result corroborates the experimental data showing increased $\mathrm{M} / \mathrm{F}$ ratios as a function of increased primary ion mass and nuclearity. Although not a true quantitative argument, qualitatively the experimental and computation trends show significant agreement.

In addition to the energy distribution of the sputtered flux, the build-up of sub-surface chemical damage is known to increase the amount of molecular fragmentation observed during subsequent analyses [32-35]. This result has primarily been observed under dynamic sputtering conditions, but can be replicated for pulsed analysis by increasing the primary ion duty cycle. In a typical RIMS experiment, the primary ion pulse lasts for 300-500 ns. After $\sim 250 \mu$ s, all of the $\mathrm{U}$ and $\mathrm{UO}_{\mathrm{x}}$ ions have traversed the flight tube and have reached the detector. At a repetition rate of $1 \mathrm{kHz}$, this means that there is a $750 \mu$ s wait until the next ion pulse starts the subsequent analysis. During this time, the ion gun can be operated continuously to increase the primary ion duty cycle of each analysis cycle to a maximum of $50 \%$; this limit is imposed by our high voltage power supplies, not by the available time window. 
Figure 5 illustrates the dependence of $\mathrm{UO}_{2} / \mathrm{U}$ as a function of primary ion dose for $\mathrm{Au}^{+}, \mathrm{Au}_{2}{ }^{+}$and $\mathrm{Au}_{3}{ }^{+}$. From this data we see that the extent of fragmentation increases with increased primary ion dose. This is primarily a result of chemical damage build-up by the continuous sputtering portion of each analysis cycle. The observed behavior can be fit to the following equation:

$\gamma=\gamma_{s s}+\left(\gamma_{0}-\gamma_{s s}\right) \exp \left(-\sigma_{f} f\right)$

where $\gamma$ is the measured $\mathrm{UO}_{2} / \mathrm{U}$ with $\gamma_{0}$, and $\gamma_{\mathrm{ss}}$ being the initial and steady-state values, respectively, $\sigma_{\mathrm{f}}\left(\mathrm{cm}^{2}\right)$ is the fragmentation cross-section and $f$ is the primary ion fluence (ions $/ \mathrm{cm}^{2}$ ). The fragmentation cross-sections were determined to be $1.98 \times 10^{-5}, 2.08 \times 10^{-5}$ and $1.92 \times 10^{-5}$ for $\mathrm{Au}^{+}, \mathrm{Au}_{2}{ }^{+}$and $\mathrm{Au}_{3}{ }^{+}$respectively. We speculate that these data result from a convolution of projectile dependent molecular fragmentation and ion-induced preferential sputtering of oxygen from the uranium oxide matrix at high ion doses [36]. Therefore, as the surface becomes chemically reduced, the amount of uranium atoms in the sputtered flux, which is indicative of the surface composition, increases with increase ion dose. The number of uranium atoms in the sputtered flux is further increased by projectile dependent molecular fragmentation from the subsequent analysis beam. In our experiment, the analysis beam and the reducing beam are the same projectile operated under different sputter conditions. We plan to verify our hypothesis by experiments where the analysis beam and the reducing beam are decoupled from one another. Unfortunately, a direct correlation between $\mathrm{M} / \mathrm{F}$ and useful yield cannot be made because the ions generated during the dynamic portion of the analysis are not being detected. However, it is likely that this observation accounts for some of the discrepancy in useful yield measurement observed between pulsed RIMS experiments and dynamic SIMS experiments.

\section{Conclusion}

The primary ion dependence of fragmentation of $\mathrm{UO}_{\mathrm{x}}$ molecules has been investigated. The results show that molecular fragmentation is decreased as the mass and nuclearity of the primary ion increases. SRIM calculations show that cluster ions deposit the majority of their energy closer to the target surface than monatomic ions. Although the transfer of energy from the cluster ions to the target atoms is more efficient, increased sputter yields partition the primary ion energy over a larger number of ejected species, resulting in less energy per sputtered 
molecule. Lowering the energy per molecule as a function of primary ion mass and nuclearity decreases the probability of molecular fragmentation and is characterized by the increased M/F ratios observed experimentally. In addition, the extent of molecular fragmentation as a function of ion dose was evaluated for several primary ions. Molecular fragmentation increases as the ion dose increases, and the relative amount of increase is projectile independent. These data suggest that sub-surface chemical damage caused by ion sputtering results in more uranium atoms in the sputtered flux of subsequent ion impacts. It is likely that RIMS measurements taken at higher ion doses will result in an increased useful yield of uranium atoms from $\mathrm{U}_{3} \mathrm{O}_{8}$ matrices.

\section{Acknowledgements}

This work was supported by the U.S. Department of Energy, Office of Basic Energy Sciences, Division of Material Sciences and Engineering under award number DEAC02-06CH11357 (D.G.W., M.R.S., and M.J.P), and by Lawrence Livermore National Laboratory under contract number DE-AC52-07NA27344, by the Laboratory Directed Research and Development Program at LLNL under project 10-SI-016, as well as with support from the Department of Energy Office of Nonproliferation Research and Development and the U.S. Department of Homeland Security (K.B.K. and I.D.H.).

\section{References}

1. Bürger, S, Riciputi, LR, Bostick, DA, Turgeon, S, McBay, EH, Lavelle, M (2009) International Journal of Mass Spectrometry 286: 70

2. Betti, M, Tamborini, G, Koch, L (1999) Analytical Chemistry 71: 2616

3. Günther-Leopold, I, Waldis, JK, Wernli, B, Kopajtic, Z (2005) International Journal of Mass Spectrometry 242: 197

4. Kraiem, M, Richter, S, Külhn, H, Stefaniak, EA, Kerckhove, G, Truyens, J, Aregbe, Y Analytical Chemistry 83: 3011

5. Pitois, Al, Heras, LAdL, Betti, M (2008) International Journal of Mass Spectrometry 273: 95

6. Tamborini, G, Betti, M, Forcina, V, Hiernaut, T, Giovannone, B, Koch, L (1998) Spectrochimica Acta Part B: Atomic Spectroscopy 53: 1289

7. Zhang, XZ, Esaka, F, Esaka, KT, Magara, M, Sakurai, S, Usuda, S, Watanabe, K (2007) Spectrochimica Acta Part B: Atomic Spectroscopy 62: 1130

8. Allen, GC, Brown, IT, Harris, SJ (1994) Nuclear Instruments \& Methods in Physics Research Section BBeam Interactions with Materials and Atoms 88: 170-173 
9. Ranebo, Y, Hedberg, PML, Whitehouse, MJ, Ingeneri, K, Littmann, S (2009) Journal of Analytical Atomic Spectrometry 24: $277-287$

10. Hedberg, PML, Peres, P, Cliff, JB, Rabemananjara, F, Littmann, S, Thiele, H, Vincent, C, Albert, N Journal of Analytical Atomic Spectrometry 26: 406

11. Ranebo, Y, Niagolova, N, Erdmann, N, Eriksson, M, Tamborini, G, Betti, M (2010) Analytical Chemistry 82: $4055-4062$

12. Savina, MR, Pellin, MJ, Tripa, CE, Veryovkin, IV, Calaway, WF, Davis, AM (2003) Geochimica Et Cosmochimica Acta 67: 3215-3225

13. Levine, J, Savina, MR, Stephan, T, Dauphas, N, Davis, AM, Knight, KB, Pellin, MJ (2009) International Journal of Mass Spectrometry 288: 36-43

14. Schumann, PG, Wendt, KDA, Bushaw, BA (2005) Spectrochimica Acta Part B-Atomic Spectroscopy 60: 1402-1411

15. Isselhardt, BH, Savina, MR, Knight, KB, Pellin, MJ, Hutcheon, ID, Prussin, SG (2011) Analytical Chemistry 83: 2469-2475

16. Andersen, HH, Sigmund, P (1965) Physics Letters 15: 237

17. Davies, N, Weibel, DE, Blenkinsopp, P, Lockyer, N, Hill, R, Vickerman, JC (2003) Applied Surface Science 203: 223-227

18. Touboul, D, Kollmer, F, Niehuis, E, Brunelle, A, Laprevote, O (2005) Journal of the American Society for Mass Spectrometry 16: 1608-1618

19. Ryan, KE, Wojciechowski, IA, Garrison, BJ (2007) Journal of Physical Chemistry C 111: 12822-12826

20. Brenes, DA, Garrison, BJ, Winograd, N, Postawa, Z, Wucher, A, Blenkinsopp, P (2011) Journal of Physical Chemistry Letters 2: 2009-2014

21. Brenes, DA, Willingham, D, Winograd, N, Postawa, Z (2011) Surface and Interface Analysis 43: 78

22. Coon, SR, Calaway, WF, Burnett, JW, Pellin, MJ, Gruen, DM, Spiegel, DR, White, JM (1991) Surface Science 259: 275

23. Coon, SR, Calaway, WF, Pellin, MJ, Curlee, GA, White, JM (1993) Nuclear Instruments \& Methods In Physics Research Section B-Beam Interactions With Materials And Atoms 82: 329-336

24. Kuhlewind, H, Kiermeier, A, Neusser, HJ (1986) The Journal of Chemical Physics 85: 4427

25. Willingham, D, Kucher, A, Winograd, N (2008) Applied Surface Science 255: 831-833

26. Czerwinski, B, Samson, R, Garrison, BJ, Winograd, N, Postawa, Z (2006) Vacuum 81: 167-173

27. Kotter, F, Benninghoven, A (1998) Applied Surface Science 133: 47-57

28. Ambartzumian, R, Furzikov, N, Letokhov, V, Puretsky, A (1976) Applied Physics A: Materials Science \& Processing 9: 335

29. Capone, F, Colle, Y, Hiernaut, JP, Ronchi, C (1999) Journal of Physical Chemistry A 103: 10899-10906 
30. Ziegler, JF, Ziegler, MD, Biersack, JP (2010) Nuclear Instruments \& Methods in Physics Research Section B-Beam Interactions with Materials and Atoms 268: 1818-1823

31. Poerschke, D, Wucher, A (2011) Surface and Interface Analysis 43: 171-174

32. Willingham, D, Brenes, DA, Winograd, N, Wucher, A (2011) Surface and Interface Analysis 43: 45

33. Willingham, D, Brenes, DA, Wucher, A, Winograd, N (2010) Journal of Physical Chemistry C 114: 53915399

34. Cheng, J, Winograd, N (2005) Analytical Chemistry 77: 3651-3659

35. Wucher, A (2008) Surface and Interface Analysis 40: 1545-1551

36. Idriss, H, Senanayake, SD, Waterhouse, GIN, Chan, ASY, Madey, TE, Mullins, DR (2007) Journal of Physical Chemistry C 111: 7963-7970 


\section{List of Figures}

Figure 1: Mass spectra obtained by ion sputtering of $\mathrm{U}_{3} \mathrm{O}_{8}$ with $15 \mathrm{keV} \mathrm{Ga}^{+}$(black), $\mathrm{Au}^{+}$(red), $\mathrm{Au}_{2}^{+}($blue) and $\mathrm{Au}_{3}{ }^{+}$(green). Characteristic mass peaks include ${ }^{235} \mathrm{U},{ }^{238} \mathrm{U},{ }^{235} \mathrm{UO},{ }^{238} \mathrm{UO},{ }^{235} \mathrm{UO}_{2}$ and ${ }^{238} \mathrm{UO}_{2}$.

Figure 2: $\quad \mathrm{M} / \mathrm{F}$ ratios for $\mathrm{Ga}^{+}, \mathrm{Au}^{+}, \mathrm{Au}_{2}{ }^{+}$and $\mathrm{Au}_{3}{ }^{+}$where the parent mass is either UO (black) or UO $($red) and the fragment mass is always $\mathrm{U}$.

Figure 3: $\quad$ SRIM calculations of the number of direct knock-ons of Ga ${ }^{+}$(black), $\mathrm{Au}^{+}(\mathrm{red}), \mathrm{Au}_{2}^{+}($blue $)$and $\mathrm{Au}_{3}^{+}$ (green) with $\mathrm{U}_{3} \mathrm{O}_{8}$ target atoms as a function of sample depth.

Figure 4: SRIM calculations of the total energy of the sputtered flux (black) versus the energy per sputtered atom (red) for $\mathrm{Ga}^{+}, \mathrm{Au}^{+}, \mathrm{Au}_{2}{ }^{+}$and $\mathrm{Au}_{3}{ }^{+}$. Each of the two y-axes indicated by the arrows are associated with the data set of the corresponding color. The lines through the data points are to guide the eye and do not represent a fit to the data.

Figure 5: $\mathrm{M} / \mathrm{F}$ ratios for $\mathrm{Au}^{+}$(red), $\mathrm{Au}_{2}{ }^{+}$(blue) and $\mathrm{Au}_{3}{ }^{+}$(green) versus primary ion dose. Solid lines of the corresponding color indicates the least squares fit of each data set to Equation 1. 
Figure 1

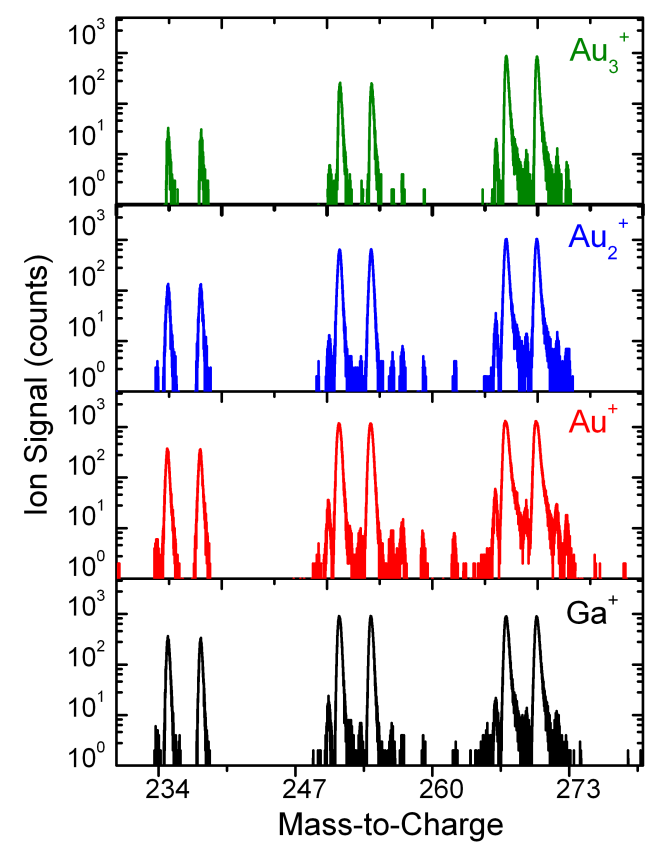

Figure 3

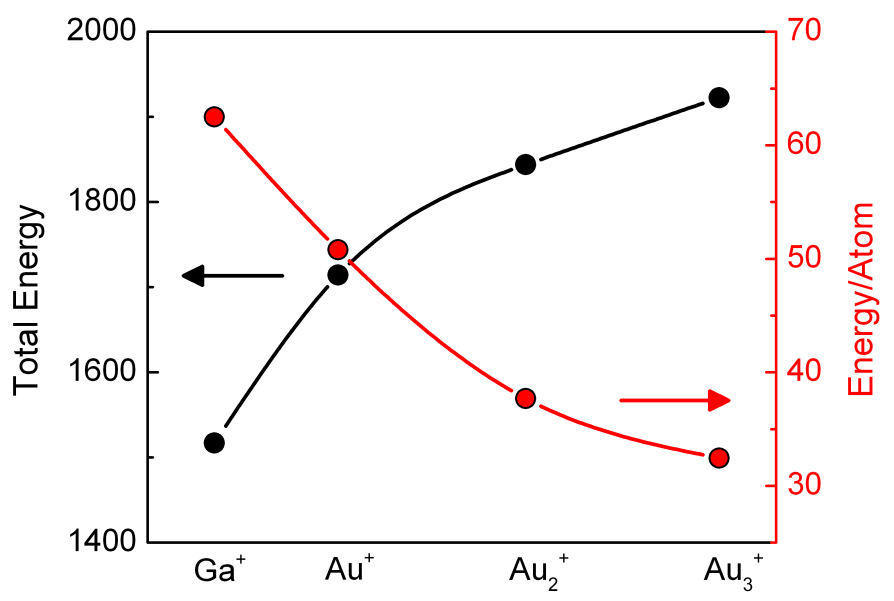

Figure 2

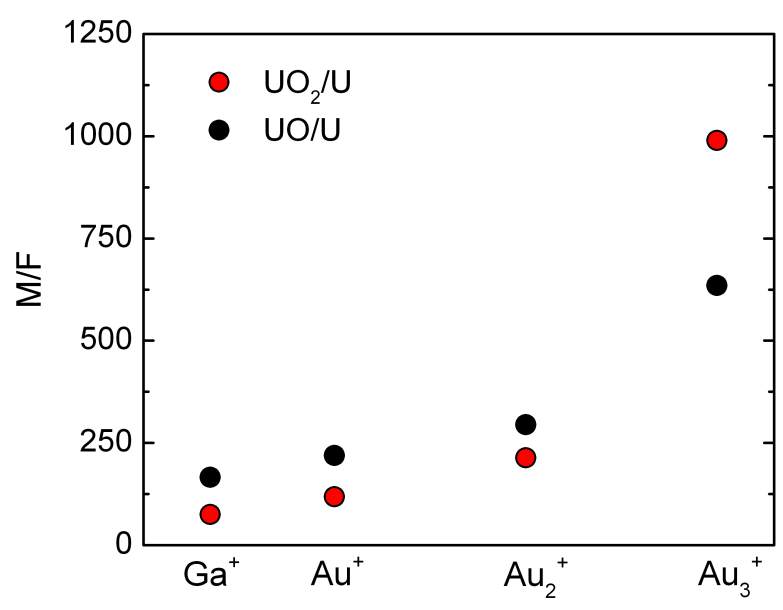

Figure 4

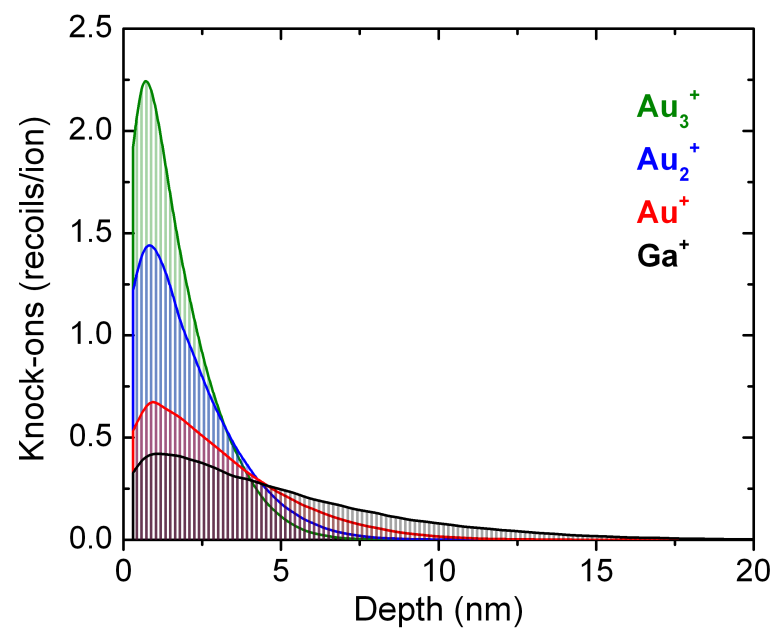


Figure 5

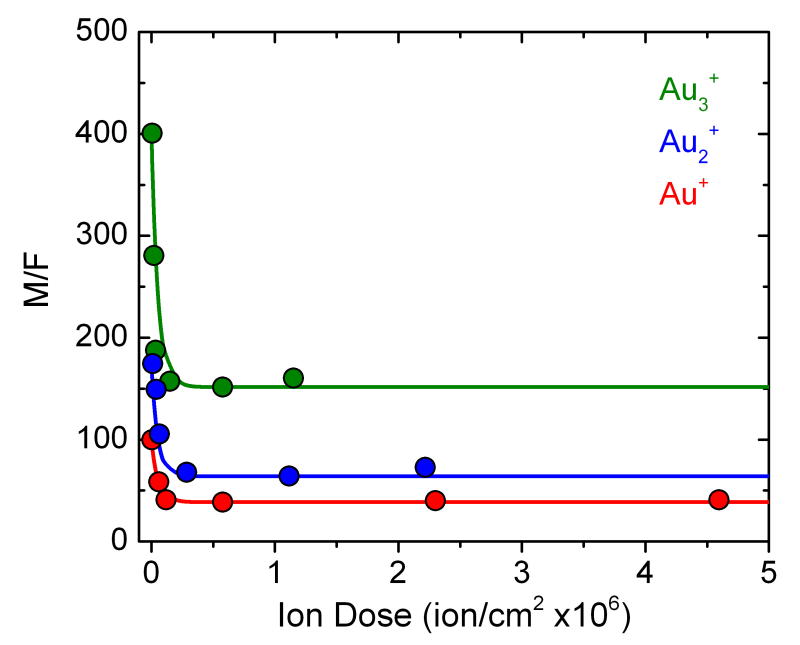

Table 1. Conversion of the experimentally measured ion signals to the actual number of sputtered neutrals within the laser volume using the saturation ionization technique. Photoionization cross sections $(\sigma)$ for $\mathrm{U}, \mathrm{UO}$ and $\mathrm{UO}_{2}$ neutrals are listed. The $\mathrm{M} / \mathrm{F}$ ratios using $\mathrm{UO}$ and $\mathrm{UO}_{2}$ as parent ions and $\mathrm{U}$ as the fragment ions are shown for each primary ion using the ion signals and the calculated number of sputtered neutrals. The percentage of uranium atoms in the sputtered flux for each primary ion is indicated.

\begin{tabular}{|c|c|c|c|c|c|c|c|c|c|}
\hline \multirow{2}{*}{\multicolumn{2}{|c|}{$\sigma\left(\mathrm{cm}^{2}\right)$}} & \multicolumn{4}{|c|}{ Ion Signals } & \multicolumn{4}{|c|}{ Sputtered Neutrals } \\
\hline & & $\mathrm{Ga}^{+}$ & $\mathrm{Au}^{+}$ & $\mathrm{Au}_{2}^{+}$ & $\mathrm{Au}_{3}^{+}$ & $\mathrm{Ga}^{+}$ & $\mathrm{Au}^{+}$ & $\mathrm{Au}_{2}^{+}$ & $\mathrm{Au}_{3}^{+}$ \\
\hline $\mathrm{U}$ & $2.1 \times 10^{-15}$ & 30628 & 35972 & 11770 & 1709 & 30692 & 36047 & 11794 & 1713 \\
\hline UO & $2.0 \times 10^{-22}$ & 96698 & 149976 & 66064 & 20657 & 508934 & 789344 & 347704 & 108721 \\
\hline $\mathrm{UO}_{2}$ & $3.0 \times 10^{-23}$ & 110194 & 203899 & 120721 & 81364 & 229570 & 424788 & 251501 & 169508 \\
\hline \multicolumn{2}{|c|}{$\mathrm{UO} / \mathrm{U}$} & 3.16 & 4.17 & 5.61 & 12.09 & 165.82 & 218.98 & 294.80 & 634.84 \\
\hline \multicolumn{2}{|c|}{$\mathrm{UO}_{2} / \mathrm{U}$} & 3.60 & 5.67 & 10.26 & 47.61 & 74.80 & 117.84 & 213.24 & 989.80 \\
\hline \multicolumn{6}{|c|}{$\%$ composition of uranium atoms } & .42 & .30 & .20 & .06 \\
\hline
\end{tabular}

